\title{
UCLA
}

Mester

Title

Día II

Permalink

https://escholarship.org/uc/item/38w627w9

Journal

Mester, 16(1)

Author

Klahr, Frida Lara

Publication Date

1987

DOI

10.5070/M3161013820

Copyright Information

Copyright 1987 by the author(s). All rights reserved unless otherwise indicated. Contact the author(s) for any necessary permissions. Learn more at https://escholarship.org/terms

Peer reviewed 


\section{Día II}

No necesito en absoluto el perdón de los dioses

Ellos hacen la luz y se estrella con todas las tinieblas

hacen niños y permiten su muerte de cada día

Si aquí mi luz fue cercenada y mi amor segado

si aquí mi carne desnuda cercada

y mi pasión filtrada por la arena

Mi camino fue mucho más estrecho

que la palabra "camino"

Bajaré al infierno

y los sedientos serán sedados

con mis labios

Los que murieron de frío serán cálidos

con las pupilas heridas de mi cuerpo

Un nombre mató mi fuego

Cruel oráculo

pero quedó la ceniza de mi deseo

Se me negó dar y se ceder

al infierno todo mi derecho a Ser.

Frida Lara Klahr

Lago de Pátzcuaro,

Octubre 86 